\title{
Life-cycle seismic costs estimation and seismic insurance model for multi-story isolated-based RC buildings
}

\author{
Jian Zhu ${ }^{12, \text { a }}$, Junhai Zhao ${ }^{1, b}$ and Jianmin Jin $^{3, c}$ \\ ${ }^{1}$ School of Civil Engineering, Chang An University, Xi An, China \\ ${ }^{2}$ School of Civil \& Hydraulic Engineering, Ningxia University, Yin Chuan, China \\ ${ }^{3}$ Earthquake Research Center, Guang Zhou University, Guang Zhou, China \\ aarrow66@163.com, b zhaojh@cha.edu.cn, ${ }^{\mathrm{a}}$ jinjm@gzu.edu.cn
}

\begin{abstract}
Keywords: Life-cycle seismic cost; Stochastic ground motion; Multi-story isolated-based buildings; Stochastic simulation; Seismic insurance premium.

Abstract. The estimation of annual average earthquake losses in life long period for simple multi-story isolated-based reinforced concrete (RC) frames based stochastic method models is the focus of the article. An innovative seismic fragility methodology is firstly adopted for seismic loss estimation, that damage of the structural and nonstructural which connected into response of the structure and peak diaphragm acceleration under a given stochastic motions use nonlinear incremental dynamic analysis to estimate damage of buildings in a detailed. Description of the uncertainty of all parameters in research through appropriate probability distributions to reach quantification of the life-cycle seismic losses expected value. Moreover, the study is also to give the expected suggested insurance premium of sample buildings in selected areas based Monte-Carlo stochastic simulation in its service lifetime.
\end{abstract}

\section{Introduction}

High seismic intensity regions and coastal regions are more vulnerability to natural disasters due to particular geographic location. Although it is not possible to completely avoid damage due to suddenly occurrence of disasters. It is however still possible to minimize their devastating effects by enhancing resilience in communities, that is, by reducing (1) system failure probability, (2) consequences of system failures, and (3) fee and time to recovery[1]. At present for better approach above targets, many researchers further push the research performance-based earthquake engineering (PBEE) forward a great step over the entire life-cycle of the buildings. In this paper, an innovative method including three aspect factors are considered for simple isolated-based buildings in China. This article is focus on a simulation-based, comprehensive research framework that aims to put the life-cycle loss estimation analysis into reality. An probabilistic simple insurance model is also reviewed based on advanced stochastic sampling concepts. This analysis aims to identify the importance of the various seismic loss risk-factors towards the overall performance of the inhabitant structural system.

\section{Life-cycle seismic loss methodology}

In consideration of complexity and different regional characteristic about life-cycle seismic loss research, a whole set of innovated life-cycle analysis procedures based stochastic probability have been raised in this article based past PBEE research results.

The methodology indeed expand research time to life-cycle of buildings based PBEE, so basically it also consist of four steps same as PBEE framework. Fig 1 shown as the methodology in this research. 


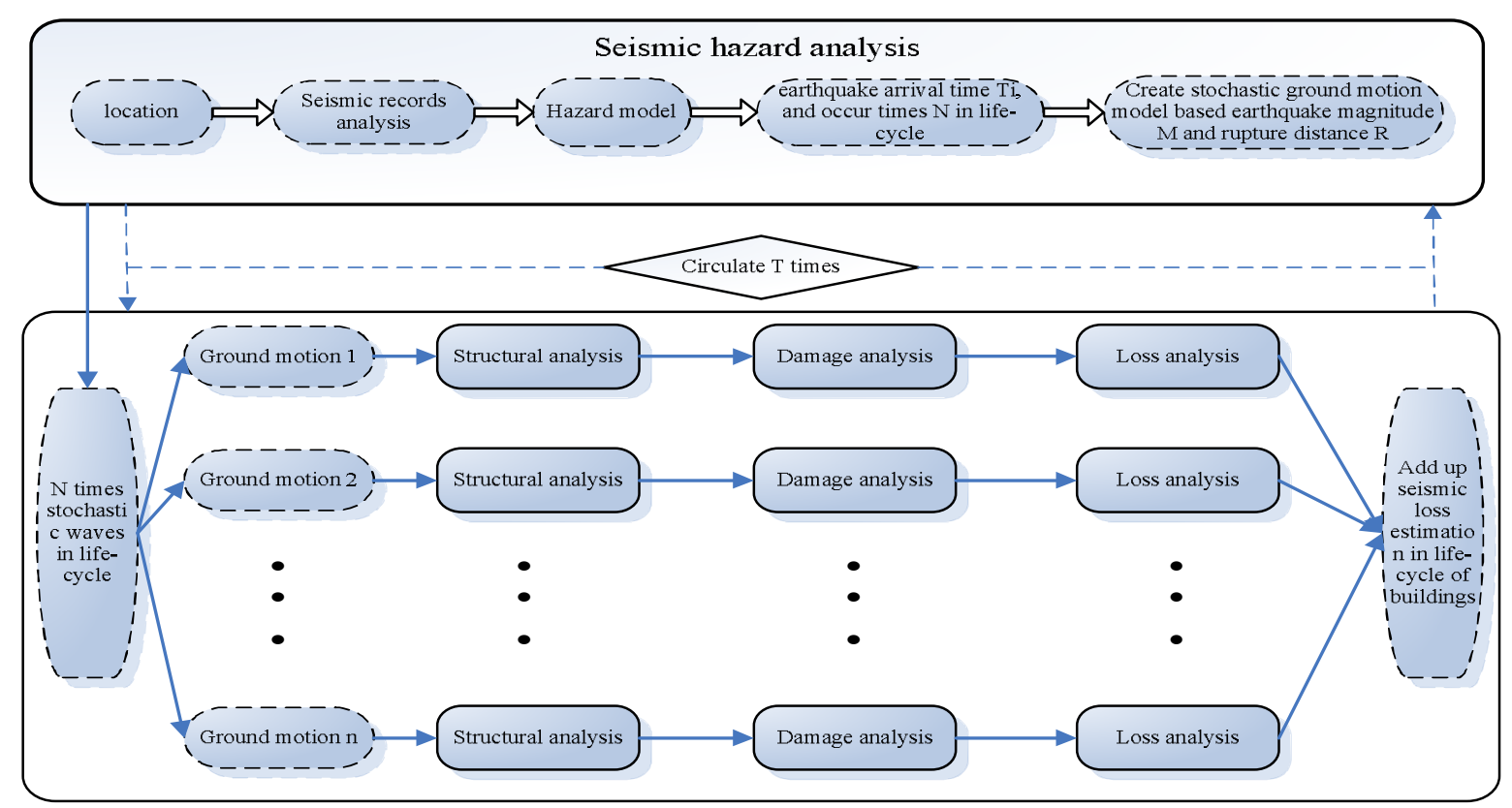

Fig.1 Framework of life-cycle loss estimation

\section{Life-cycle seismic hazard model}

Predictable ground motions in the special site firstly are considered in research as outer excitation to test structural system's performance. The life-cycle model of a seismic hazard specifies (1) the random arrival times, $T_{1}, T_{2}, L$, of individual events at a site during a reference period $\tau$, and (2) the random properties of the ground motion hazards under considerations at $T_{1}, T_{2}, L$. The random properties involves: stochastic quantification of the earthquake intensity measure (IM) based precious activity matrix at the site and creating stochastic ground motions consistent with the intensity hazard.

Monte Carlo algorithms can be used for generating samples of lifetime seismic hazard at a given site during a reference period $\tau$. Therefore, a life-cycle hazard sample consists of the arrival times of individual events and the properties defining their probability law.

The activity matrix of seismic hazard at a given site delivers the annual rate of occurrence for events of the hazard corresponding to earthquake magnitude $M$ and rupture distance $r$. We can plot activity matrices against the properties which completely define the probability law of the hazard at the site. The plot of mean annul rate of occurrence of earthquake for all $(M, r)$ at the site is called the site seismic activity matrix.

The average number of events per year irrespective of the values of $(M, r)$ is

$$
v=\sum_{i=M, r} v_{i_{M}, i_{r}}
$$

We assume that the events in time according to a homogeneous Poisson counting process $\{N(\tau), \tau \geq 0\}$ of intensity $\vee$ so that

$$
P(N(\tau)=n)=\frac{(v \tau)^{n}}{n !} \exp (-v \tau), \quad n=0,1,2, \ldots
$$

The approach corresponds to a 'source-based' stochastic ground motion model, developed by considering the physics of the fault rupture at the source as well as of the propagation of seismic waves through the entire ground medium till the structural site. It is based on a parametric description of the ground motion's radiation spectrum $A(f ; M ; r)$, dependent on the earthquake magnitude $M$ and rupture distance $r$ and expressed as a function of the frequency $f$.This spectrum consists of many factors that account for the spectral effects from the source (source spectrum) as well as propagation 
through the earth's crust. The duration of the ground motion is addressed through an envelope function $e(r ; M ; r)$, which is also depends on $M$ and $r$. More details on them are shown in article [2]. These frequency and time domain function $A(f ; M ; r)$ and $e(r ; M ; r)$, completely describe the model and their characteristics are provided by predictive relationships that relate them directly to the seismic hazard such as $M$ and $r$.
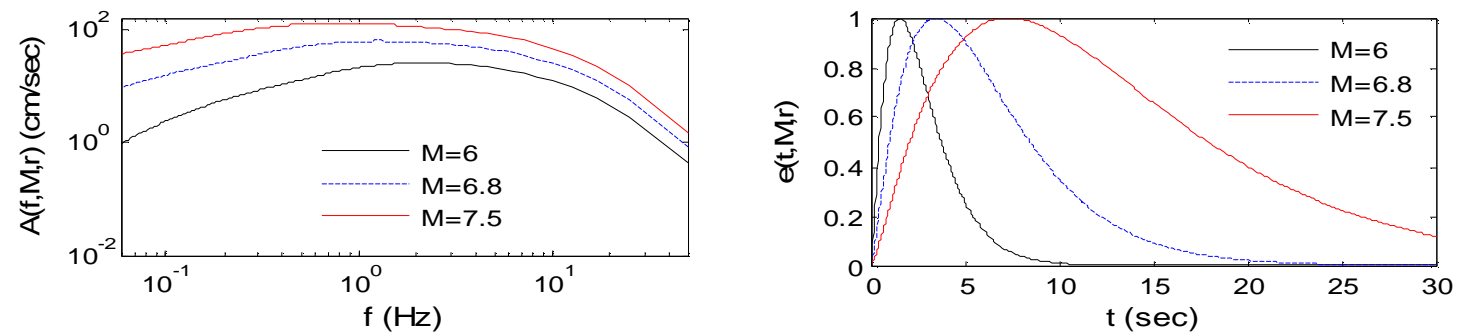

Fig.2 Envelopes with different earthquake magnitude and rupture distance
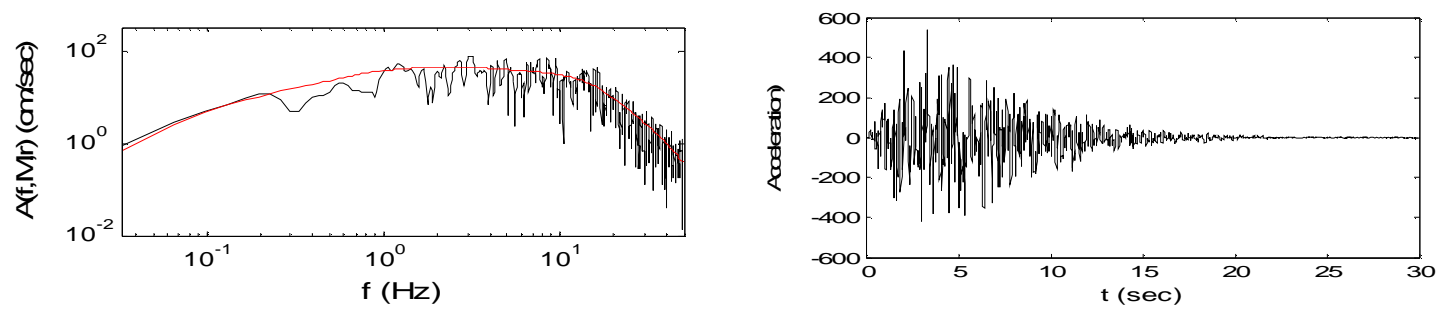

Fig.3 A sample wave of stochastic ground motions

The activity matrix of seismic hazard at a given site delivers the annual rate of occurrence for events of the hazard corresponding to earthquake magnitude $M$ and rupture distance $r$, which completely define the probability law of the hazard at the site. The plot of mean annual rate of occurrence of earthquake for all $(M, r)$ at the site is called the site seismic activity matrix. In this work buildings located in Yinchuan region in western China are chosen because of high seismic hazardous of local region. Seven hazard levels (HL:72/50, 38/50, 25/50, 16/50, 10/50, 5/50, 2/50) corresponding to the different annual probability of exceedance and maximum inter-storey drift ratio in local area are calculated based China seismic code and shown in paper [7]. Therefore, the maximum DIs calculated at each hazard level have an annual exceedance probability equal to that of the current HL.

\section{Simple multi-story isolated-based RC frames}

For the calculate example, the simple six storey reinforced concrete building used in this research. The structure corresponds to towns' and villages' RC buildings wide used in Western China comply with the China seismic code (GB50011-2010) [3].
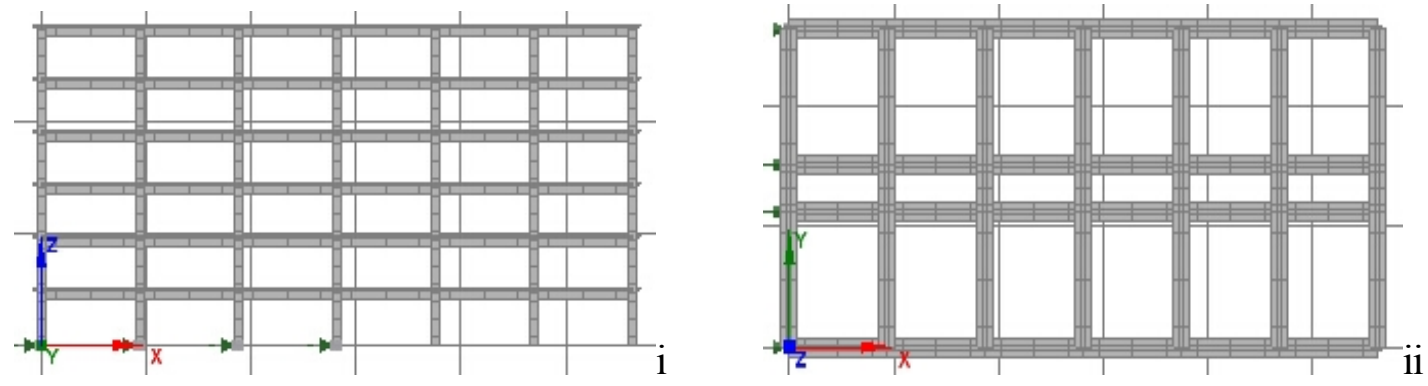

Fig.4 The RC isolated-based model-(i) front view and (ii) plan view

In this work, 3D moment resisting isolated-based framed buildings have been considered in order to obtain the seismic insurance model and influence of various sources of uncertainties on the life-cycle cost. Steel of class with yield stress of 335-400 Mpa and modulus of elasticity equal to $210 \mathrm{Gpa}$ has 
been considered, while concrete of cubic strength of 20-25 Mpa and modulus of elasticity equal to 30 Gpa. The structural layout of the building represents six bay in longitudinal direction with 6-8m span lengths and three bay in transverse direction with $6-2.5-6 \mathrm{~m}$ span lengths respectively. The storey height is $3.3 \mathrm{~m}$. The column elements size is $0.5 \mathrm{~m} \times 0.5 \mathrm{~m} \sim 0.5 \mathrm{~m} \times 0.7 \mathrm{~m}$. The beam size is $0.25 \mathrm{~m} \times 0.6 \mathrm{~m}$. The slab thickness is equal to $12 \mathrm{~cm}$, while in addition to the self weight of the beams and the slabs, a distributed permanent load of $2 \mathrm{kN} / \mathrm{m}^{2}$ due to floor-finishing partitions and live load of $1.5 \mathrm{kN} / \mathrm{m}^{2}$. For the analysis a three dimensional fiber model is created in Seismostruct software shown in Fig 4.

The lead core rubber isolators are chosen as GZY500 and located in foundation of buildings. Four parameters determined based test data of manufactory: Equivalent damping ratio is $27 \%$, initial stiffness is $7750 \mathrm{kN} / \mathrm{m}$ including $\pm 10 \%$ variance, yield force is $62.6 \mathrm{KN}$ and post yield coefficient is 0.1 .

\section{Incremental dynamic analysis}

In the seismic assessment of structures a wide range stochastic man-made waves and seven HL level are considered in order to take into account the uncertainties. The main objective of a IDA method is to define a curve through a relation between the seismic intensity level and the corresponding maximum response of the structural system. The intensity level and the structural response are described through an intensity measure (IM) and an engineering demand parameters (EDP) which refers also as damage index (DI). Incremental analysis are implemented through the following steps in this research: (i) Construct the local typical digital finite element model for performing nonlinear dynamic analyses; (ii) select a group of stochastic man-made waves fitted with local response spectrum; (iii) select a proper intensity measure and an engineering demand parameter; (iv) employ an appropriate algorithm for selecting the record scaling factor in order to obtain the IM-EDP curve by performing the least required nonlinear dynamic analyses and (v) employ a summarization technique for exploiting the multiple waves results. In this work, the $S_{a}\left(T_{1}, 5 \%\right)$ for damping equal to $5 \%$ is selected as IM indicator, since it is the most commonly used intensity measure in practice today for the analysis of buildings. At the same time, two kind of damage index: the maximum inter-storey drift $\theta_{\max }$ and PDA are chosen as EDPs, which are based on the maximum deformation of different damage limit states.

For example actual physical damage calculation process of RC isolated-based frames using IDA with Friuli Italy-02 (1976) earthquake record is explained next carefully. The IM scale factor increase from 1 to 9 in IDA analysis. The whole damage results of maximum inter-storey drift ratio and PDA of every storey are shown in Fig.5.That means all kind of seismic intensity waves have impacted on buildings in life-cycle period. So the structural and non-structural damage of every floor of buildings can be calculated from the two EDPs parameters. The maximum ISD \% of whole structure locates in second floor and the peak diaphragm acceleration (PDA) in the top floor at the same time. So that mean the most structural damage lie in second floor and the severe non-structural damage in top storey. The tendency of the seismic vulnerability changed more obvious than ever.

The relation between the drift ratio limits with the limit states. employed in this study is partly based on the work of Ghobarah[4] for ductile RC moment resisting frames, and at the same time vast stochastic sampling based Monte Carlo method based local construction code in Western China also impact the limit state setting in this research. The relation of the limit state with the values of the PDA is partly based on the work of Elens and Meskouris[5]. 

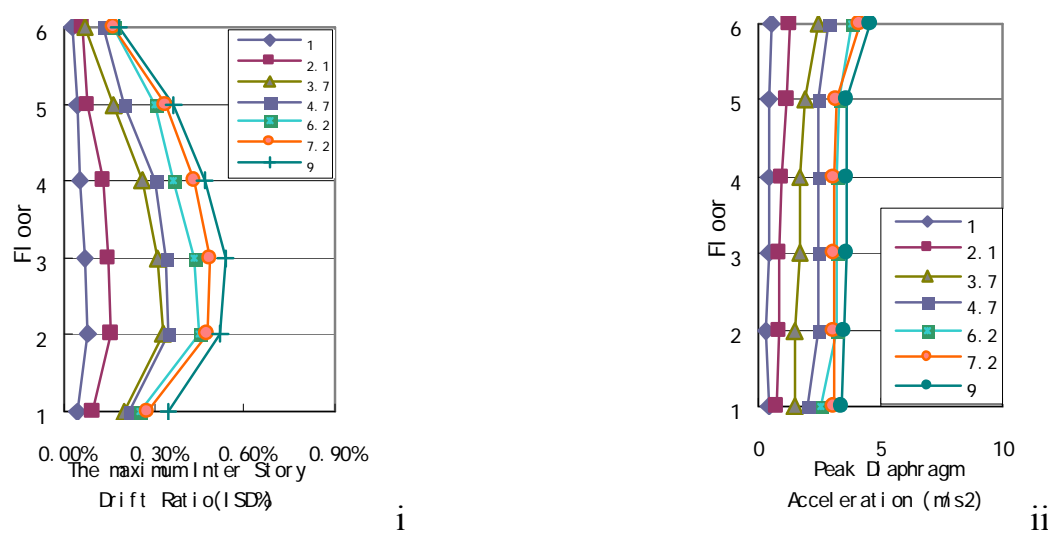

Fig.5 The Maximum inter-storey drift ratio and Peak Diaphragm acceleration (i:ISD\%; ii: PDA)

\section{Life-cycle seismic cost assessment \& conclusion}

The life-cycle seismic cost can be obtained finally through incremental dynamic analyses based above equations in research [8].

A more detailed description of the different cost evaluation for each limit state cost can be found in Tab IV. The basic cost mentioned in Table IV refers to the first component of the calculation formulas. While they are given in Chinese Yuan (CNY). The values of the mean damage index, loss of function, down time, expected minor injury rate, expected serious injury rate and expected death rate used in this study are based on [6-7].

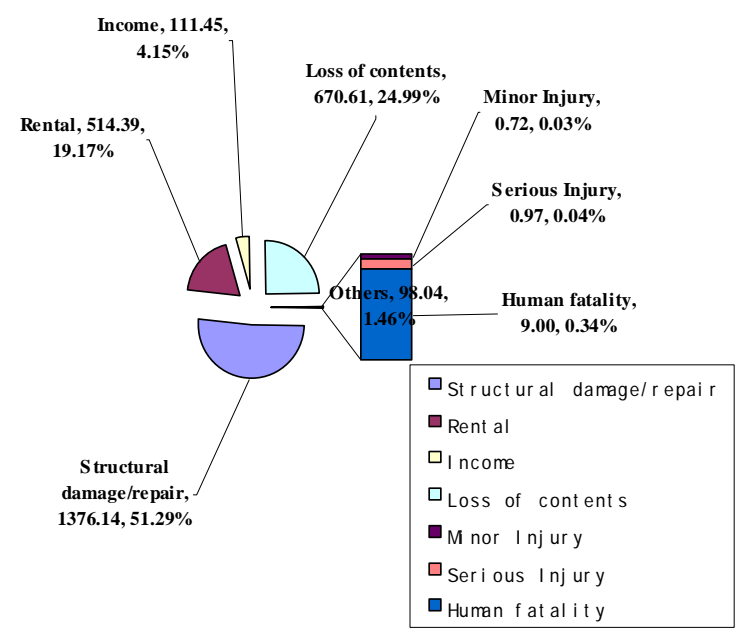

Fig. 6 The constitution of multi-story isolated-based RC buildings' LCC in Yinchuan region

After study local statistics data of construction engineering in Yinchuan which located in high seismic hazardous region of western China. In this research $2500 C N Y / m^{2}$ is considered as $C_{I N}$, meantime $\pm 10 \%$ variance is also included. 
Tab. 1 SLCC of multistory isolated-based examples Statistics characteristics comparison

\begin{tabular}{c|c|c|c}
\hline \multicolumn{4}{|c}{ multistory isolated-based buildings } \\
\hline & $\begin{array}{c}\text { average } \\
\text { Yuan }\end{array}$ & $\begin{array}{c}\text { median } \\
\text { Yuan }\end{array}$ & CoV \% \\
\hline$C_{\text {dam }}^{i}$ & 1387.02 & 1376.14 & $1.075 \%$ \\
\hline$C_{r e n}^{i}$ & 520.92 & 514.39 & $6.264 \%$ \\
\hline$C_{i n c}^{i}$ & 114.24 & 111.45 & $7.913 \%$ \\
\hline$C_{c o n}^{i, \theta}$ & 673.68 & 670.61 & $1.134 \%$ \\
\hline$C_{i n j}^{i}$ & 0.73 & 0.72 & $4.488 \%$ \\
\hline$C_{f a t}^{i}$ & 10.05 & 9.97 & 4.032 \\
\hline$C_{t o t}$ & 2706.64 & 2683.28 & $0.680 \%$ \\
\hline
\end{tabular}

The statistics median covered area of typical sample multi-story isolated-based building is $3600 \mathrm{~m}^{2}$. The annual average LCC is $1.48 \mathrm{CNY} / \mathrm{m}^{2}$ after calculation using above procedure from Fig.6, and annual median LCC is $1.47 \mathrm{CNY} / \mathrm{m}^{2}$. There will add up additional reasonable $50 \%$ fee if insurance companies will establish catastrophe insurance in the near future. The final insurance payment per people is about 77-78 CNY every year in considering of local life endurance in this research on base of average living space per person equal $30 \mathrm{~m}^{2}$. The result is considered in acceptable level for local people in Yinchuan city of western China as research sample region finally.

\section{Acknowledgements}

This work was financially supported by the National Natural Science Foundation of China (51468050), the Research Project of Guangzhou Municipal Universities(1201620162) and the Shanxi Province Post-doctoral Science Foundation.

\section{References}

[1] Porter KA, Kiremidjian A S, LeGrue J S., "Assembly-based vulnerability of buildings and its use in performance evaluation," Earthquake Spectra, vol.18, pp.291-312,2001.

[2] Boore DM. Simulation of ground motion using the stochastic method. Pure Appl Geophys, vol.160,pp.635-676,2001.

[3] Ministry of Construction P.R.China,"Code for seismic design of buildings (GB50011-2010)," China Construction Press Publication, Beijing, 2010.

[4] Ghobarah A., "On drift limits associated with different damage levels,"Proceedings of the international workshop on performance-based seismic design, June 28-July 1,2004.

[5] Elenas A, Meskouris K,"Correlation study between seismic acceleration parameters and damage indices of structures," Eng Struct, vol.23,pp.698-704,2001.

[6] Federal Emergency Management Agency, "FEMA 227:A benefit-cost model for the seismic rehabilitation of buildings," Washington, DC, Building Seismic Safety Council,1992. 
[7] Z. Jian, Z.J.Hai and J.J.Min, "Life-cycle seismic costs estimation and seismic insurance model for simple RC buildings in Western China" 2016 International Conference on Architectural Engineering and Civil Engineering (AECE-16), Advances in Engineering Research (AER), Atlantis press publishied,Shanghai China, vol:72, Dec $10,2016$.

[8] Lagaros, ND and Mitropoulou, CC, "The effect of uncertainties in seismic loss estimation of steel and reinforced concrete composite buildings," Structure and Infrastructure Engineering, Vol. 9, No. $21,546-556,2013$. 